\title{
OPEN Mechanical and optimization studies of polypropylene hybrid biocomposites
}

\begin{abstract}
Adeolu A. Adediran ${ }^{1 凶}$, Abayomi A. Akinwande ${ }^{2 \bowtie}$, Oluwatosin A. Balogun², Oladele S. Bello², Miracle K. Akinbowale ${ }^{2}$, Olanrewaju S. Adesina ${ }^{1}$ \& Ayotunde A. Ojo ${ }^{3}$

Towards developing a polymeric matrix characterized by high strength to cost ratio, polypropylene (PP) was hybridized with low-cost particulate snail shell (PSS) and kenaf fiber (KF) via compression moulding at $180^{\circ} \mathrm{C}$ and $0.2 \mathrm{MPa}$. The developed composites were grouped into three and labeled as mix 2, 4, and 10. Each group entailed the blend of 5, 10, 20, and 30 wt\% KF with 2, 4, 10 wt\% PSS respectively. From the results, it is observed that the hardness value was enhanced by the blend of 5 to $30 \mathrm{wt} \% \mathrm{KF}$ and 2, 4, and 10 wt\% PSS. However, 2 wt\% PSS mix with 5 to $30 \mathrm{wt} \% \mathrm{KF}$ resulted in progressive improvement in impact, compressive, flexural, and tensile strengths values. The $4 \mathrm{wt} \%$ PSS yielded consecutive increase in impact, compressive and flexural strength when combined with 5 and 10 wt\% KF. However, it was observed that subsequent addition of 20 and 30 wt\% KF led to a marginal reduction in the strength values. The tensile strength attained optimum value when $4 \mathrm{wt} \%$ PSS was commixed with 30 wt $\%$ KF. Conversely, the combinations of 10 wt\% PSS with 5, 10, 20, and 30 wt\% KF had no significant improvement to the mechanical properties of PSS/KF-bio-PP composite (except for hardness) siring strength decrease. Taguchi optimization revealed that the collage of $4 \mathrm{wt} \%$ PSS and 10 wt\% KF presented optimum mix for hybrid bio-PP composite.
\end{abstract}

Fundamental engineering materials are in most cases classified as metals, ceramics, and polymers. These classes of material find application in various aspect of engineering and the choice are based on their properties. The selection of one class of material over another is on account of comparative advantage in terms of property and cost. Metals are characterized by high strength, ductility, and closed packed structures ${ }^{1}$ while ceramics are hard, have good heat and corrosion resistance, dense and brittle ${ }^{2}$. Polymer, on the other hand, is light in terms of weight, possesses a high strength-to-weight ratio, low cost, and has resistance to corrosion ${ }^{3}$. Nowadays, polymer has found successful engagement in most engineering applications as substitutes to metals because of cost implication and corrosion resistance 4 . Engineering polymers are employed in biomedical and biomimetics, aerospace, automobile, electricity and electronics, structures, clothing, and material development ${ }^{5,6}$. Polymeric materials are further classified into thermoplastics, thermosets, and elastomers. Thermoplastics like polypropylene, polyethylene, and polyvinyl chloride have high demand based on their everyday use. Polypropylene (PP) for instance, is applied in packaging, automobile, textile, medical and other forms of application ${ }^{7,8}$. Being an engineering material, it has good chemical and corrosion resistance, it is tough, and possesses good fatigue and heat resistance ${ }^{9}$. According to Maddah ${ }^{10}$, energy-saving policy in automobile manufacturing necessitates the use of lightweight engineering materials for fuel optimization. Based on this and owing to the lighter weight of PP when compared with most polymeric materials, $\mathrm{PP}$ is being used for different parts of the vehicle. Some of the areas of use in cars are dashboards, batteries, AC ducts, doors, and quarter panels ${ }^{11-13}$. Also, thermoplastic olefin produced from PP is utilized in car bumpers, air drums, and rocket panels ${ }^{14,15}$. In aerospace, PP is employed for sandwich composite panels while in structures, it has application as fibers for reinforcing concrete ${ }^{16,17}$. For better performance in service, base polymeric matrix undergoes structural alteration and modification via different processes one of which is reinforcement with different materials; infusing synthetic and agro by-products in the matrix. Agro-by-product reinforcement of polymer matrix in form of bio fillers and bio fibers are encouraged based on their low cost and reuse. The agro-based products cause some modification at the microstructural level bringing about enhanced property of base material. Authors Onuegbu and Igwe ${ }^{18}$ investigated the effect of snail shell powder on the properties of PP. The snail shell powder was sieved to $15 \mu \mathrm{m}, 30 \mu \mathrm{m}$, and $42 \mu \mathrm{m}$ after which

${ }^{1}$ Department of Mechanical Engineering, Landmark University, Omu-Aran, Kwara State, Nigeria. ${ }^{2}$ Department of Metallurgical and Materials Engineering, Federal University of Technology, Akure, Ondo State, Nigeria. ${ }^{3}$ Department of Mechanical Engineering, Ekiti State University, Ado Ekiti, Ekiti State, Nigeria. ${ }^{\varpi}$ email: dladesoji@gmail.com; abypublication@gmail.com 
they were added at varying proportions of 10, 20, 30, and $40 \%$ respectively. The mechanical properties were assessed and the result revealed progressive appreciation in tensile, impact, and flexural strengths. Analysis of the results showed a higher improvement of properties with reduced particle sizes. Optimum mechanical properties were attained at $40 \%$ of the powder for all particle sizes considered with $15 \mu \mathrm{m}$ having the highest performance. Studies from Onuegbu and Nwanonenyi ${ }^{19}$ examined the mechanical properties of PP by adding pulverized groundnut husk at 2, 4, and $6 \%$. Particle sizes were varied at $0.2,0.4,0.6,0.8$, and $1 \mathrm{~mm}$. The result showed enhancement in tensile, flexural, and impact strengths on account of adding up to $6 \mathrm{wt} \%$ of the powder. From the outcome, the inclusion of filler contributed to the property improvement of the PP matrix. On the other hand, coconut shell particles have been reported as a strengthener in the production of polymer matrix composites $^{20}$. Varying weight percent of coconut shell particles at 10, 20,30, and $40 \mathrm{wt} \%$ were utilized in the production of polymer-based composites. The results revealed that irrespective of size, an increasing proportion of the particle improved the yield, tensile and flexural strengths even as hardness was enhanced ${ }^{20}$. In recent times, cardanol was used with untreated and $\mathrm{NaOH}$ treated coir particles at different sizes of 25,50 , and $75 \mu \mathrm{m}^{21}$. Their studies revealed an enhancement in tensile, flexural, and impact strengths respectively. Further observation revealed that $25 \mu \mathrm{m}$ treated coir particles performed optimally. Equally, 3, 6, 9, 12, and $15 \mathrm{wt} \%$ snail shell powder were observed to improve tensile strength in recycled waste plastic developed for automobile application ${ }^{12}$. Similarly, compressive, impact, and flexural strengths, and hardness were enhanced by the blend of 10, 20, 30, 40 , and $50 \mathrm{wt} \%$ of carbonized eggshell filler ${ }^{22}$. Researchers also investigated the influence of agro-fiber as reinforcement in polymers reporting various outcomes. Natural fibers like sisal, banana, and coir were employed in reinforcing epoxy resin in the literature ${ }^{23}$. Tensile strengths, flexural strengths, and hardness of the epoxy composites were enhanced by the fibers. Another common fiber is bagasse ${ }^{24}$. Authors Akinwande et al. ${ }^{25}$ examined the effect of proportion and length of coir fiber in PP towards property enhancement for automobile application. Experimental results depicted that the inclusion of fiber at 5 to $20 \%$ played a major role in improving tensile and flexural properties. Impact resistance was enhanced up to $25 \mathrm{wt} \%$ of fiber while hardness showed progressive improvement with coir fiber fraction of 5 to $30 \mathrm{wt} \%$. Optimization engaged in via response surface methodology denoted fiber length $34.85 \mathrm{~mm}$ at $25.76 \%$ proportion is most desirable. Kenaf/polypropylene composite was developed by authors Lee et al. ${ }^{26}$. As observed, 10, 15, 20, and $25 \mathrm{wt} \%$ kenaf fiber-enhanced tensile and flexural properties over neat PP depicting the fact that kenaf fibers in PP ensued positive modification of mechanical properties for engineering application. From the findings of Ramli et al. ${ }^{27}$, PP was reinforced with oil palm fiber matrix. From the outcome, $40 \mathrm{wt} \%$ fiber reinforced PP showed better properties than control PP matrix with regards to flexural strength, tensile and flexural moduli. Jute fiber employed by Kabir et al. ${ }^{28}$, led to the enhancement of tensile and flexural properties. From these literatures, it's clear that agro-by products in terms of fiber, play major role in the improvement of mechanical properties of developed polymeric composites. Additionally, hybrid polymer composites of fiber and particulate fillers blend had been a subject of investigation for years; as investigated by Balaji et al. ${ }^{29}$ which entailed a study on bagasse fiber/coconut shell hybrid biocomposites. On the other hand, hybridized polypropylene with coir fiber and yam peel particulate as reported by Adediran et al..$^{30}$, showed an improvement in impact strength as well as tensile and flexural properties. In Adeosun et al's work ${ }^{31}$, hybrid polyester composite with the blend of coconut and snail shell particulate in unsaturated polyester was reported. By contrast, coconut shell particulate outperformed snail shell particulate especially tensile strength and Brinell hardness, while snail shell outperformed coconut shell with regards to bending and impact strengths. Generally, optimum results were obtained with portions between 10 and $20 \mathrm{wt} \%$ for the two particulates proving that dual particulate contributes to property enhancement of polymers. It is well known that, agro-fibers and particulate fillers have a promising future as reinforcement in polymers. This study, therefore, involved property evaluation of polypropylene matrix reinforced with kenaf fiber and particulate snail shell. The choice of polypropylene is on the dint of low cost and its availability in the Nigerian market. Improving low-cost PPmatrix with agro-byproduct can lead to the development of useful engineering products which are affordable. In addition to the property evaluation, statistical analysis was carried out on obtained results to derive an optimum combination of kenaf fiber and particulate snail shell.

\section{Materials and methods}

Materials. Input materials engaged in this research are stearic acid, kenaf fiber, snail (African giant snail) shell, and virgin polypropylene (PP) pellet. Kenaf fiber and snail shell were procured from a nearby farm in Omu-Aran, Kwara State, Nigeria while stearic acid and virgin PP pellet was procured from a merchant in Omu Aran, Kwara State. Procured kenaf fiber was washed in warm water to removed attached impurities and sundried for 2 days. Afterwards, the fiber was cut to $25 \mathrm{~cm}$ length and treated with $0.8 \%$ stearic acid according to procedures followed by Salman et al. ${ }^{32}$ where surface treatment of kenaf fiber with $0.8 \%$ achieved optimum performance. Treated fiber (Fig. 1a), was washed with distilled water and oven-dried at $60^{\circ} \mathrm{C}$ for $8 \mathrm{~h}$. The snail shells were cleansed in warm water to remove impurities present and sun dried for 3 days after which the dried shells were crushed and pulverized followed by sieving using a laboratory electric sieve shaker. Snail shell particulate sieved to $-25 \mu \mathrm{m}$ (Fig. 1b), were collected, oven-dried at $50{ }^{\circ} \mathrm{C}$ for $2 \mathrm{~h} .25 \mu \mathrm{m}$ size was adopted on account of observations noted in Udhayasankar et al. ${ }^{21}$. Figure $2 \mathrm{a}-\mathrm{d}$ show the morphological images and energy dispersive spectra of the input materials. The chemical constituents of treated kenaf fiber used in the study is as presented in Table 1 while Table 2 shows the chemical composition of the particulate snail shell.

Surface treatment of kenaf fiber revealed a rough surface of the fiber occasioned on account of the removal of wax and impurities. The process also led to a reduction in lignin and hemicellulose content (Table 1), thereby decreasing the hydrophilic tendency of the fiber. Figure $2 \mathrm{c}$ highlights the EDX spectrum of KF from which it is noted that calcium ( $\mathrm{Ca}$ ) showed a high peak, suggesting the presence of calcium-based compound which contributes to the strength enhancement of PP matrix. Figure $2 \mathrm{~b}$ reveals the microstructural features of PSS. 


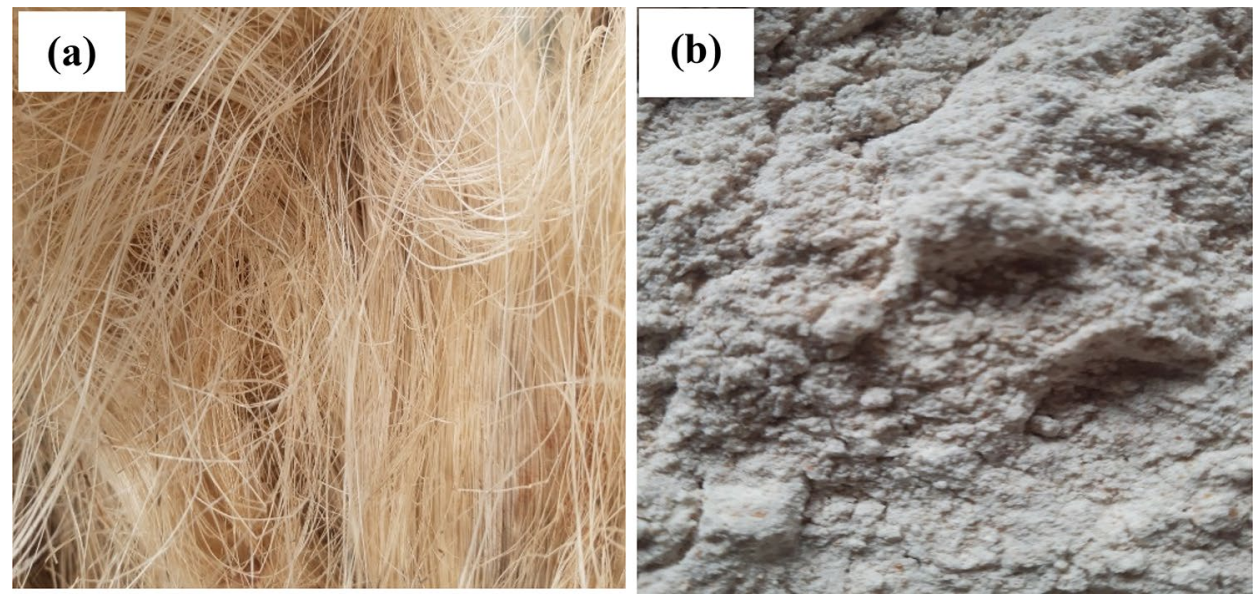

Figure 1. Image of input materials (a) kenaf fiber (b) Particulate snail shell.
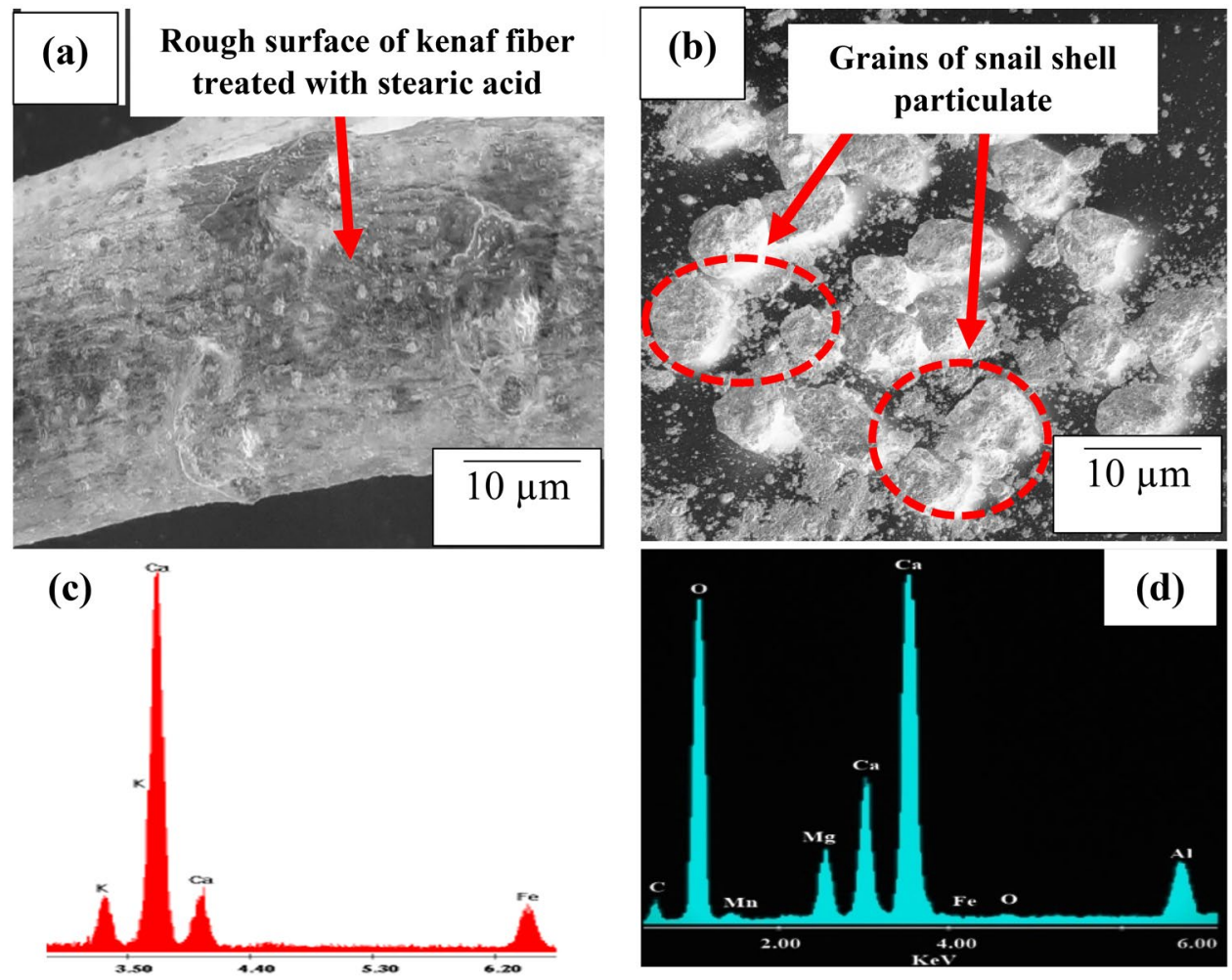

Figure 2. Morphological images of input materials (a) kenaf fiber (b) Particulate snail shell and EDX spectra for (c) kenaf fiber (d) Particulate snail shell.

\begin{tabular}{|l|l|l|l|l|l|l|}
\hline Chemical constituents & Cellulose & Hemicellulose & Lignin & Moisture & Ash & Others \\
\hline Amount & 52.3 & 22.4 & 7.9 & 6.4 & 3.4 & 7.8 \\
\hline
\end{tabular}

Table 1. Chemical constituents of treated kenaf fiber used in the study.

The shape of the particles is mostly spherical of which the shapes promoted infilling of pores in matrix reducing inter-particle distance, effect of which reflected in property enhancement. From Fig. 2d, peak showing calcium $(\mathrm{Ca})$ and oxygen $(\mathrm{O})$ are observed to be higher than other elements. The resultant effect of the $\mathrm{Ca}$ and $\mathrm{O}$ presence shows the presence of $\mathrm{CaO}$ as confirmed in Table 2, contributing to the strength and hardness of composites when PSS was imbued in the PP matrix. 


\begin{tabular}{|l|l|}
\hline Compound & Amount \\
\hline $\mathrm{CaO}$ & 59.8 \\
\hline $\mathrm{SiO}_{2}$ & 0.89 \\
\hline $\mathrm{Al}_{2} \mathrm{O}_{3}$ & 0.16 \\
\hline $\mathrm{Fe}_{2} \mathrm{O}_{3}$ & 0.78 \\
\hline $\mathrm{MnO}$ & 0.06 \\
\hline $\mathrm{MgO}$ & 0.96 \\
\hline $\mathrm{Na}_{2} \mathrm{O}$ & 1.05 \\
\hline Others & 4.81 \\
\hline Loss on ignition & 31.33 \\
\hline
\end{tabular}

Table 2. Chemical composition of particulate snail shell employed in the present investigation.

Mix proportion. The development process involved blending of particulate snail shell (PSS) and kenaf fiber (KF) in polypropylene (PP) matrix at varying proportions using waring laboratory blender (8011EG). The control mix was produced as pure polypropylene (PP) with no KF and PSS admix. Three group mixes of samples were considered and are labeled as mix 2 composites for the first group, mix 4 composites for the second group and mix 10 composites for the third group. Group labeled mix 2 composites entailed the blend of $0,5,10,20$, and $30 \% \mathrm{KF}$ by weight of PP with 2 wt. PSS. Similarly, groups labeled mix 4 composites consist of the blend of 4 wt $\%$ PSS and $0,5,10,20$, and $30 \% \mathrm{KF}$ and mix 10 composites contained the blend of the same proportion of KF and $10 \%$ constant PSS weight fraction. 2, 4, and $10 \mathrm{wt} \%$ PSS were considered based on conclusion made by ChrisOkafor et al. ${ }^{33}$ in which mechanical property optimization of low-density polyethylene matrix was realized by the incorporation of 2 to $10 \mathrm{wt} \%$ snail shell powder.

Production process. Compression moulding machine (NG-BU-P11) operated at a temperature of $180{ }^{\circ} \mathrm{C}$ and pressure of $0.2 \mathrm{kPa}$ for $10 \mathrm{~min}$ on each sample was employed. $180^{\circ} \mathrm{C}$ was adopted because temperature trials above $180^{\circ} \mathrm{C}$ produced burnt samples and below produced less compacted samples. Dump bell shape mould $150 \mathrm{~mm}$ length and $3 \mathrm{~mm}$ thickness was used in the preparation of samples for the tensile test. Samples for flexural and impact were prepared using a mould of dimension $150 \times 50 \times 3\left(\mathrm{~mm}^{3}\right)$ and $63.5 \times 12.7 \times 2.5\left(\mathrm{~mm}^{3}\right)$ according to Adediran et al. ${ }^{34}$. Samples for compressive strength were produced in moulds $40 \mathrm{~mm}$ diameter and $80 \mathrm{~mm}$ length. Wax was robbed in the mould cavity while the top and base of the mould were covered with Teflon sheets before compression. Samples were left to cure for $24 \mathrm{~h}$ sequel to careful removal from moulds and cleaning.

Property characterization. Izod impact strength. Izod impact strength was appraised by subjecting notched samples (V-shaped) to impact employing Hounsfield balance impact tester (3915) in line with ASTM D $256-10^{35}$. The pendulum of the tester was set at $165^{\circ}$ to fracture samples and impact energy to fracture was measured. An average of three samples was recorded for each mix proportion.

Tensile and flexural strength. A universal testing machine (Instron 3369 series) was used in the test in line with ASTM D $3039 \mathrm{M}-17^{36}$ applying a load of $100 \mathrm{~N}$ at a crosshead speed of $5 \mathrm{~mm} / \mathrm{min}$. Flexural samples were subjected to a three-point bending load of $1 \mathrm{kN}$. A crosshead speed of $10 \mathrm{~mm} / \mathrm{min}$ was adapted and a span length of $100 \mathrm{~mm}$ was maintained for all samples. The test was done in accordance with the ASTM D 790-17 $7^{37}$ procedure. An average of three samples were noted for each mix proportion.

Hardness. The hardness of the developed composite was probed as par ASTM D 2240-15e $1^{38}$ employing shore Durometer apparatus. The samples were indented five times on the surface and the average value was obtained.

Compressive strength. Quasi-static compression was examined on cylindrical samples produced as prescribed by ASTM D 695-15 $5^{39}$. Samples were subjected to compressive load at a strain rate of $0.1 \mathrm{~s}^{-1}$ and piston speed of $0.25 \mathrm{~m} / \mathrm{s}$. An average of three samples were recorded for each mix proportion.

Microstructural analysis. Microstructural analysis was carried out with the use of High magnification fluorescence microscope $(\mathrm{E}-807 \mathrm{Y})$ operated at $5.0 \mathrm{kV}$ and magnification of $\times 5000$.

\section{Results and discussion}

Microstructural and property evaluation. Figure 3 presents the microstructural images of the fibers in the composites developed.

Figure $3 \mathrm{a}-\mathrm{d}$ reflects the images of mix 2 composites, it was observed that there is even dispersion of PSS around the fiber which led to even stress transfer between PSS and KF even under deformation. This observation is typified in the investigation carried out by Balaji et al. ${ }^{29}$ and Anuar et al. ${ }^{46}$. In their study, the inclusion of kenaf fiber at 5 to $20 \mathrm{wt} \%$ in maleic anhydride grafted polypropylene led to enhancement of strength of composites. Additionally, kenaf fiber of 10,20,30, and $40 \mathrm{wt} \%$ was observed to boast composites strength in Salman et al..$^{32}$, 

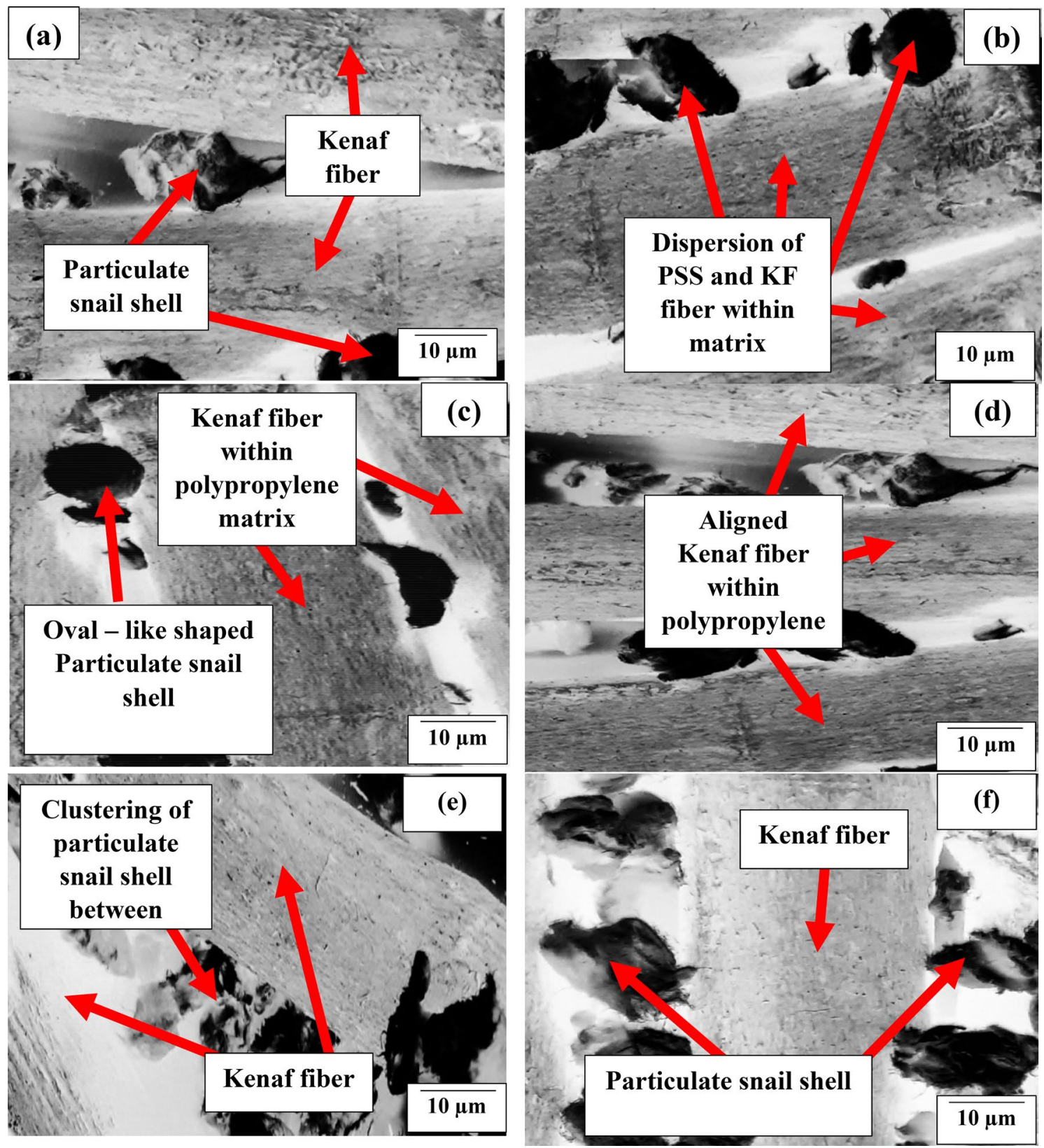

Figure 3. Microstructural image of polypropylene-PSS/KF composites developed, (a-d) reflects the images of mix 2 composites; (e-h) show the mix 5 composites containing $5 \mathrm{wt} \%$ of the particulate; (i-l) present morphological representation of the mix 10 composite prepared with $10 \mathrm{wt} \%$ PSS. 

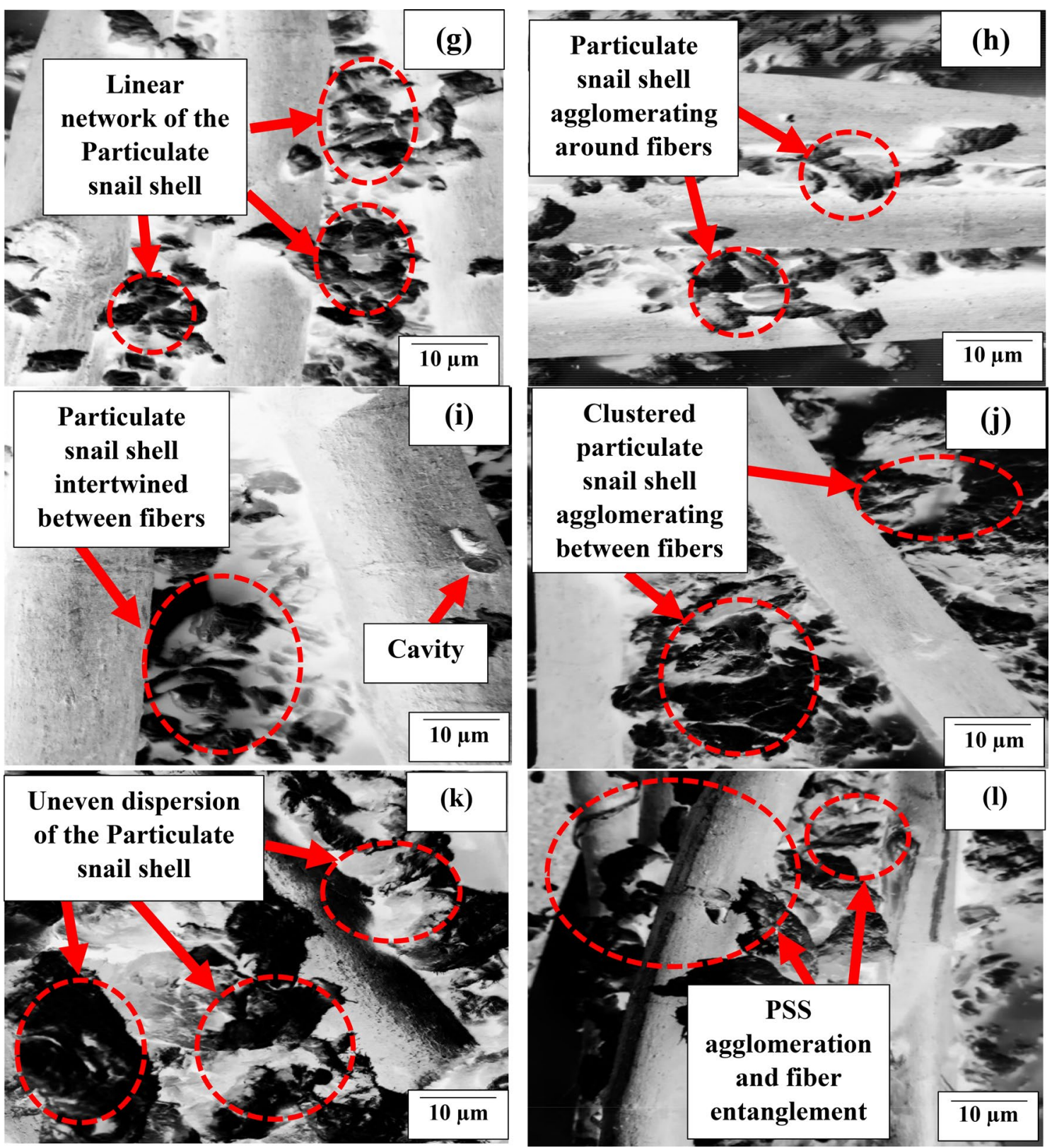

Figure 3. (continued)

though contrary observation was reported in Kim and $\mathrm{Cho}^{47}$ where 10, 20, and $30 \mathrm{wt} \%$ kenaf fiber manifested a progressive decrease in strength. Figure $3 \mathrm{e}-\mathrm{h}$ depict the mix 5 composites containing $5 \mathrm{wt} \%$ of the particulate. Figure $3 e$ portrays agglomeration of PSS between kenaf fiber serving as point of stress concentration. Figure $3 \mathrm{f}$ reflects the particulate dispersion and interaction with kenaf fiber within matrix enhancing bond strength. This is held responsible for improved performance in the strength properties. Figure $3 \mathrm{~g}$ presents particulate agglomeration around fiber serving as points of agglomeration, affecting the strength performance negatively. Figure $3 \mathrm{~h}$ displays how the particulate are displayed along the fibers, depicting reasons for improved strength. Meanwhile, Fig. 3i-l present morphological representation of the mix 10 composite prepared with $10 \mathrm{wt} \%$ PSS. The major feature observed is the agglomeration of particles appears alongside the fibers. This is responsible for low performance of the mix 10 samples.

Hardness response of polypropylene-PSS/KF composites. As observed in Fig. 4a, hardness was enhanced by the introduction of KF in the PP matrix. Mix 2 composites group entailed blend of $2 \mathrm{wt} \%$ PSS and 5, 10, 20, and 30 wt $\%$ KF. It was noted that increasing KF loading amounted to the enhancement of hardness. This trend is based on the interlink between fiber and matrix enhanced by alkaline treatment of the fiber which promoted interfacial adhesion between the fiber and polypropylene matrix. A similar finding from the investigation of Balaji et al. ${ }^{29}$ portrayed an uptrend in hardness with increasing banana fiber loading of 5, 10, 15, and $20 \mathrm{wt} \%$ in epoxy matrix; corroborating the outcome of this study. 

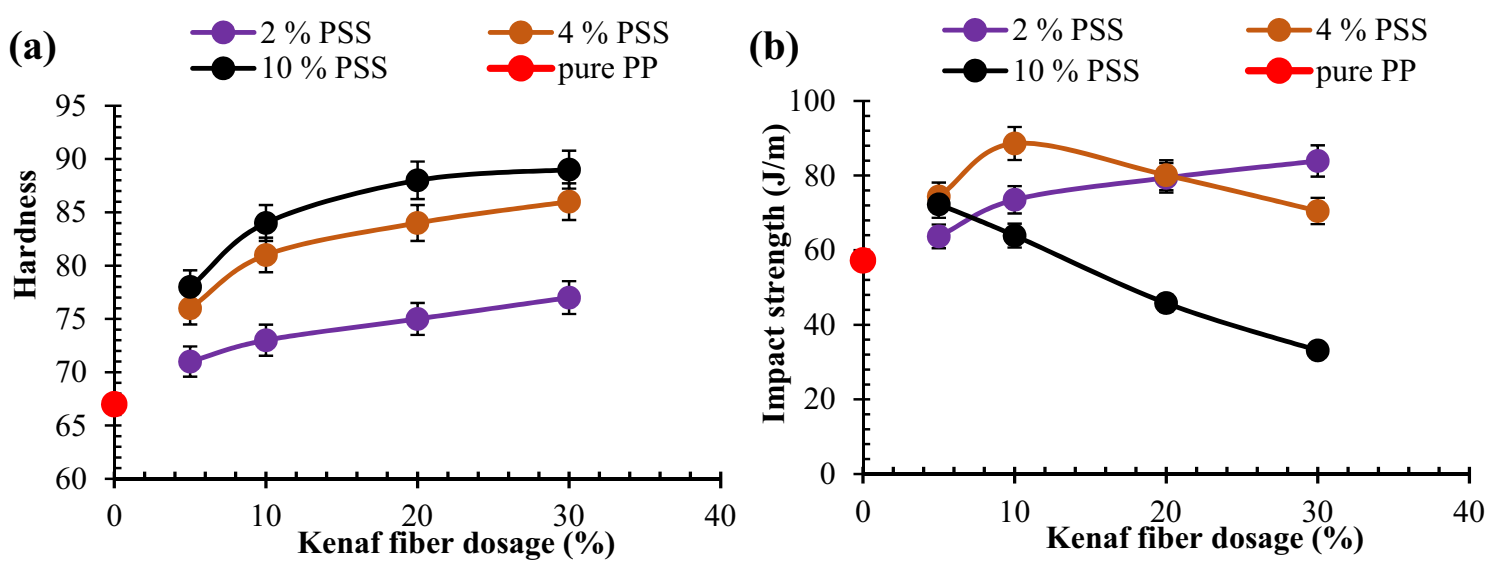

Figure 4. Graphical plot for the interaction between admix of kenaf fiber (KF)/particulate snail shell (PSS) at varying proportion and (a) hardness (b) impact strength.

\begin{tabular}{|l|l|r|r|l|l|}
\hline Source & DF & \multicolumn{1}{c|}{ Adj SS } & Adj MS & F-value & $P$ value \\
\hline $\mathrm{A}$ & 1 & 168.69 & 168.686 & 12.88 & 0.005 \\
\hline $\mathrm{B}$ & 1 & 391.11 & 391.109 & 29.86 & 0.000 \\
\hline $\mathrm{A}^{\star} \mathrm{A}$ & 1 & 26.17 & 26.172 & 2.00 & 0.188 \\
\hline $\mathrm{B}^{*} \mathrm{~B}$ & 1 & 63.90 & 63.903 & 4.88 & 0.052 \\
\hline $\mathrm{A}^{*} \mathrm{~B}$ & 1 & 306.22 & 306.219 & 23.38 & 0.001 \\
\hline Error & 10 & 130.98 & 13.098 & & \\
\hline Total & 15 & 2178.93 & & & \\
\hline
\end{tabular}

Table 3. ANOVA for harness.

From the result obtained, the interaction between the KF and PSS led to the enhancement of hardness. It was reported that Shore D hardness showed an enhancement as fiber content increased from 0 to $20 \mathrm{wt} \%{ }^{40,41}$. Similarly, Durowaye et al. ${ }^{42}$ corroborated the findings of this study as date palm fiber loading showed improvement of hardness in polyester composite developed in their investigation. Findings from Swain and Biswas ${ }^{43}$ and Chelliah ${ }^{44}$ linked the improvement in hardness to the cross-link of fiber with the polymer chains resulting in a complex network.

Present study revealed infusion of 5, 10, 20, and $30 \mathrm{wt} \% \mathrm{KF}$ in the PP matrix depicted 6.0, 9.0, 11.9, and 14.9\% uptrend in the value with respect to the pure PP (control sample). This delineates the fact that inclusion of kenaf fiber with PSS in polypropylene matrix ensues improvement in hardness. In the case of mix 4 composites ( $4 \mathrm{wt} \%$ PSS) which involved commix of $4 \mathrm{wt} \%$ PSS at the constant amount and varying KF dosage of 5, 10, 20, and 30 wt $\%$, it is revealed that increasing KF portion resulted in the progressive rise in values. As highlighted in Fig. 4a, intermix of $4 \mathrm{wt} \%$ PSS further promoted hardness since values reported for mix 4 composites are higher than the values of mix 2 composites. This showed that the presence of PSS also enhanced hardness which is associated with the $\mathrm{CaO}$ presence of the particulate (Table 3 and Fig. 2d). Furthermore, hard snail shell particulate presence in PP matrix led to close packing thereby enhancing cohesion between particles consequence of which led to boosting the property. The Coalesce of 5, 10, 20, $30 \mathrm{wt} \% \mathrm{KF}$ and $4 \mathrm{wt} \%$ PSS offered 9.0, 16.4, 17.9, and 17.9\% boast to hardness; giving higher value than the mix 2 counterpart. The observation corroborates the study carried out by Nwanonenyi et al. ${ }^{45}$ which explicated enhancement of hardness of low-density polyethylene matrix by the reason of adding periwinkle shell particles in the dosage of 2 to $16 \mathrm{wt} \%$.

Figure $4 \mathrm{a}$ also show values for mix 10 composites ( $10 \mathrm{wt} \% \mathrm{PSS}$ ) which contained the blend of $10 \mathrm{wt} \%$ particulate snail shell at a fixed amount and 5, 10, 20, $30 \mathrm{wt} \% \mathrm{KF}$; the result depicted an uptrend in hardness with fiber loading. In comparison with values of mix 4 composites, mix 10 composites exhibited higher hardness values at each proportion of kenaf fiber mix. Commix of $10 \mathrm{wt} \%$ PSS and 5, 10, 20, $30 \mathrm{wt} \% \mathrm{KF}$ amounted to 13.4, 23.9, 26.9 , and $32.8 \%$ respectively over pure PP.

Impact resistance response of polypropylene-PSS/KF composites. Figure $4 \mathrm{~b}$ highlights the relationship between impact strength and KF/PSS dosage. Kenaf fiber dosage of 5, 10, 20, and $30 \mathrm{wt} \%$ in the presence of $2 \mathrm{wt} \%$ PSS demonstrated uptrend in impact strength; yielding 11.1, 28.3, 38.6, and 46.4\% upgrade respectively relative to the value of pure PP. The result can be traced to enhanced interfacial adhesion between fiber and matrix promoting even stress distribution. Furthermore, as observed in Fig. $4 \mathrm{~b}$, admixing of $4 \mathrm{wt} \%$ particulate snail shell and kenaf fiber at 5 and $10 \mathrm{wt} \%$, as depicted in mix 4 composites, revealed further enhancement of 
(a)

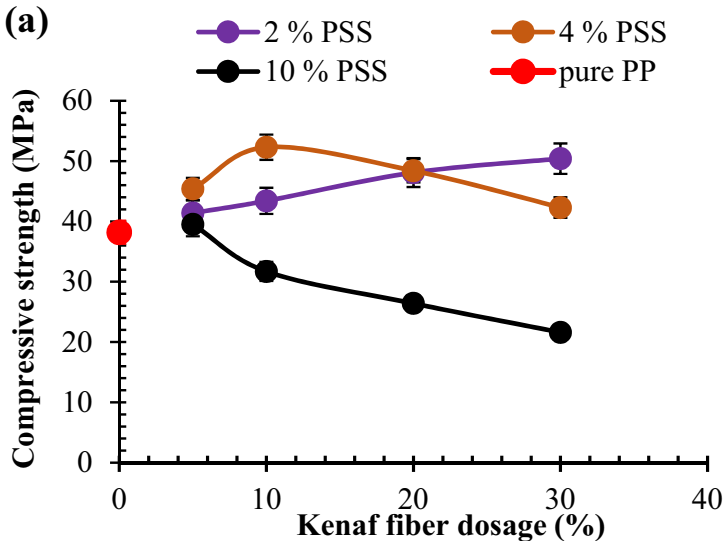

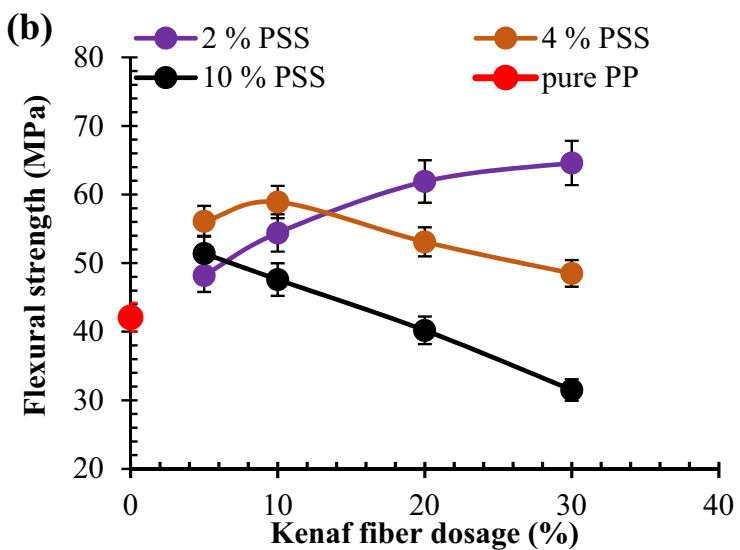

Figure 5. Graphical plot for the interaction between admix of kenaf fiber (KF)/particulate snail shell (PSS) at varying proportion and (a) compressive strength (b) flexural strength.

strength by 29.8 and $52.6 \%$ respectively relative to pure PP. The attainment is based on two factors, one of which is the interlocking of the fiber with matrix chain promoting resistance to high strain rate coupled with even distribution of the fibers. Second is the even dispersion of the PSS particulate within the matrix enhancing reinforcement/matrix interaction. Figure 3e,f identified the image of samples doped with $4 \mathrm{wt} \%$ PSS and 5 and $10 \%$ KF respectively. There is particulate dispersion within the matrix which contributed to interaction between the reinforcement and matrix. This is further boosted by the arrest of cracks by the fibers. Further intermix of $4 \mathrm{wt} \%$ PSS with 20 and $30 \mathrm{wt} \% \mathrm{KF}$ resulted in a 7.0 and $17.5 \%$ reduction in strength relative to the value obtained when $4 \mathrm{wt} \%$ PSS and $10 \mathrm{wt} \% \mathrm{KF}$ was infused; though the value was still an enhancement of 43.8 and $27.6 \%$ over pure PP. Figure 3g,h depicts points of fiber entanglement and PSS clustering/agglomeration owing to larger volume fraction occupied by the two inputs which may cause segregation and agglomeration. These features serve as points of stress concentration eventually reducing the strength of the materials.

For mix 10 composites which were doped with $10 \mathrm{wt} \%$ fixed proportion of PSS, it is evident from Fig. $4 \mathrm{~b}$ that $5,10,15$, and $20 \mathrm{wt} \% \mathrm{KF}$ had progressive reduction in strength. The reason for this is stress concentration as a result of fiber entanglement and particulate agglomeration between fibers as revealed in Fig. 3i-l. Therefore, collage of 10\% PSS and 5, 10, 20, and $30 \mathrm{wt} \%$ KF demonstrated a negative influence on impact strength. Meanwhile, peak impact strength was achieved at intermix of $4 \mathrm{wt} \% \mathrm{KF}$ and $10 \mathrm{wt} \% \mathrm{PSS}$.

With respect to the findings from Daramola et $\mathrm{al}^{48}, 44.4 \%$ optimum enhancement of impact strength was observed with the use of chitosan microparticles $(3.5 \mu \mathrm{m}$ average diameter) whereas in present study, optimum enhancement of $54.4 \%$ enhancement was realized for the same strength. Likewise, optimum impact strength enhancement attained in present study is superior to $16.7 \%$ improvement realized in Husseinsyah et al. ${ }^{49}$ when $10 \mathrm{wt} \%$ chitosan filler was added to polypropylene matrix. Comparative result of Amri et al. ${ }^{50}$ reflected $20 \%$ optimum enhancement in impact strength of polypropylene matrix when $10 \mathrm{wt} \%$ chitosan was added, a value lower than optimum improvement realized in this study.

Compressive strength of polypropylene-PSS/KF composites. Few studies carried out on compressive strength of polymer composites has shown compelling outcomes. The report from $\mathrm{Dash}^{51}$, revealed that the mix of banana fiber in epoxy at 5 and $10 \%$ vol. fraction fortified the epoxy composites containing teak wood dust. It was noted that 5 and $10 \%$ banana fiber yielded enhancement of 7 and $14.9 \%$ in compressive strength at $10 \%$ teak wood dust. According to the study, 20\% fixed teak wood dust combining with 5 and $10 \%$ banana fiber, kindled $5 \%$ reduction in and $13.1 \%$ increase in compressive strength respectively. Similarly, study of Adediran et al..$^{34}$, noted that an increase in dosage of bamboo fiber resulted in an insignificant contribution to the compressive strength while particulate distribution in matrix unfurled significant effect on the strength.

In this study, Fig. 5 a revealed that 5 to $20 \mathrm{wt} \%$ KF loading in mix 2 composites had an uptrend in compressive strength, amounting to an increment of $8.3,13.6,23.1$, and $27.5 \%$ over neat PP. The progression is ascribed to the enhanced stress distribution based on the fiber presence. The influence of kenaf fiber on compressive strength was further boasted on inoculation of $4 \mathrm{wt} \%$ PSS in the matrix (mix 4 composites) as revealed in Fig. 5a. The 5 and $10 \mathrm{wt} \%$ KF yielded 18.8 and 36.9\% improvement over pure PP accordingly. The implication of this is that coalesce of $4 \mathrm{wt} \%$ PSS and 5; $10 \mathrm{wt} . \% \mathrm{KF}$ enhanced compressive strength owing to $\mathrm{CaCO}_{3}$ presence in PSS which contributed to strength value. Also, the ensuing close packing of particles and fiber interlock with polymer chains resulted in cohesive interaction between particles and fiber, engendering even stress propagation as obtained in Fig. 3e,f respectively. It is noteworthy that coagulation of PSS and fiber entanglement in Fig. 3g,h is associated with depreciation in strength when 20 and $30 \mathrm{wt} \% \mathrm{KF}$ is mixed with $4 \mathrm{wt} \% \mathrm{PSS}$ in PP matrix. Thus, yielding 7.4 and 19.1 decrease in values obtained at $10 \mathrm{wt} \% \mathrm{KF} / 4 \mathrm{wt} \% \mathrm{PSS}$. The coexistence of $4 \mathrm{wt} \% \mathrm{PSS} / 10 \mathrm{wt} \% \mathrm{KF}$ in PP matrix had an improvement of $15.2 \%$ over values on the infusion of $4 \mathrm{wt} \% \mathrm{PSS} / 5 \mathrm{wt} \% \mathrm{KF}$. As observed in Fig. $5 \mathrm{a}$ of this work, $4 \mathrm{wt} \%$ PSS $/ 10 \mathrm{wt} \%$ fiber ensued strength increase of $36.9 \%$ over neat PP. Intermix of 5, 10, 20, and $30 \mathrm{wt} \%$ kenaf fiber and $10 \mathrm{wt} \%$ PSS led to a reduction in compressive strength (Fig. 5a) on account of coagulation of particles as revealed in Fig. 3i-l respectively. The infuse of 5, 10, 20, and $40 \mathrm{wt} \% \mathrm{KF}$ in mix 10 composites 


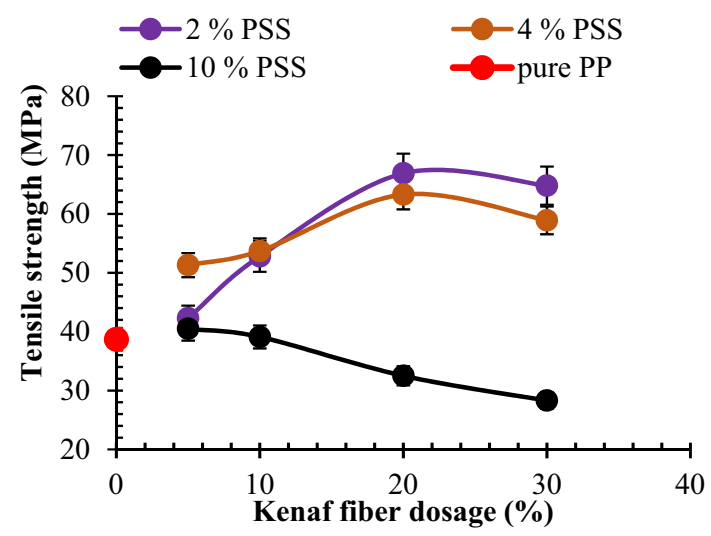

Figure 6. Graphical plot for the interaction between admix of kenaf fiber (KF)/particulate snail shell (PSS) at varying proportion for the Tensile strength.

led to $13.3,21.7,12.8$, and $3.7 \%$ depreciation in strength. The maximum strength was attained at $10 \mathrm{wt} \% \mathrm{PSS} / 4$ wt $\% \mathrm{KF}$ in PP matrix as indicated in Fig. 5a.

Flexural response of polypropylene-PSS/KF composites. Natural fibers have proved to be good agents in improving the flexural properties of polymers ${ }^{29,52-54}$. Findings from Sushanta ${ }^{55}$ revealed progressive enhancement of flexural strength of PP matrix reinforced with banana/glass fibers corroborating the observations reported in the present study. From Mir et al.'s study, kenaf fiber inclusion (KF) resulted in strength enhancement for KF in the proportion of $5,10,20$, and $30 \mathrm{wt} \%$.

In the present investigation, the presence of KF in mix 2 composites reflected a consecutive rise in flexural strength with fiber loading which occurred on the dint of fiber-matrix chain network formed, coupled with enhanced adhesion between KF and PP matrix (Fig. 5b). These proportion yielded 14.4, 29.2, 47.0, and 53.4\% improvement in flexural strength respectively, with respect to pure $\mathrm{PP}^{41}$. It is evident that the evaluation of mix 4 composites ( $4 \mathrm{wt} \%$ PSS) displayed enhancement in flexural strength on the infusion of 5 and $10 \mathrm{wt} \% \mathrm{KF}$. In contrast, subsequent addition of 20 and $30 \mathrm{wt} \% \mathrm{KF}$ amounted to 7.8 and $16.2 \%$ decline relative to $10 \mathrm{wt} \% \mathrm{KF}$ value. In comparison, mix 4 composite samples blended with $4 \mathrm{wt} \%$ (PSS) performed better than mix 2 counterparts ( $2 \mathrm{wt} \%$ PSS) when 5 and $10 \mathrm{wt} \% \mathrm{KF}$ was infused. This is based on enhanced interparticle cohesion owing to closed packing afforded by particulate presence.

Particulate addition has been reported in some studies to enhance flexural strength as noted by Obasi ${ }^{56}$. It was reported that incorporation of $0,5,10,15,20$, and $25 \mathrm{wt} \%$ peanut husk powder in low-density polyethylene resulted in the progressive rise in flexural strength with $25 \mathrm{wt} \%$ of the powder kindling up to $63.3 \%$ enhancement. Similarly, findings of Asuke et al. ${ }^{57}$ revealed the same trend when 0, 5, 10, 15, 20, and $25 \mathrm{wt} \%$ of carbonized and uncarbonized fish bone powder was infused into polypropylene matrix. At $25 \mathrm{wt} \%$, enhancement of 53.8 and $35.9 \%$ were realized for both carbonized and uncarbonized respectively. These reports are in tandem with the findings showcased in the present study.

As noted in Fig. 5b, for mix 4 (4 wt\% PSS) mix, blend of $4 \mathrm{wt} \%$ PSS and 5, 10, 20 and $30 \mathrm{wt} \%$ KF showed progressive reduction in strength. Meanwhile with respect to flexural strength of neat PP, 5 and 10 wt $\%$ KF dosage instigated 22.1 and $13.1 \%$ increase in strength while additional dose of 20 and $30 \mathrm{wt} \% \mathrm{KF}$ in the blend led to 5.4 and $25.2 \%$ decrease in strength value when compared with the value of neat PP. The aforementioned observations are hinged on agglomeration of the PSS particles and entanglement of fiber as obtained in Fig. 3i-1 respectively. Maximum flexural strength is attained when $10 \mathrm{wt} \% \mathrm{KF}$ is co-blended with $4 \mathrm{wt} \%$ PSS which is based on the interplay between kenaf fiber which serves as crack arrester and particulate snail shell which enhanced cohesion between particles and also played a major role in impeding dislocation movement. Shyang et al. ${ }^{58}$ studied the effect of natural hydroxyapatite on mechanical performance of poly (methyl methacrylate) biocomposites. Hydroxyapatite content from 5 to $20 \mathrm{wt} \%$ ensued progressive reduction in flexural strength and strain contrary to observation realized in this study.

Response of polypropylene-PSS/KF composites to tensional stress. The result of tensile strength against KF/PSS is as presented in Fig. 6. Evaluation of mix 2 composites (2 wt\% PSS) exhibited a steady increase in strength with KF loading up to $20 \mathrm{wt} \%$. This observation is engendered by interfacial adhesion between filler and matrix coupled with fiber dispersion in matrix enhancing stretching. Similarly, there is a strong interlink between fibers and the polymer chains. Findings from Haque et al. ${ }^{59}$, Haque et al. ${ }^{60}$, Haque and Islam ${ }^{61}$ revealed that fiber inclusion in polymer matrix up to $20 \mathrm{wt} \%$ ensued enhancement of tensile strength. Findings from Balaji et al. ${ }^{29}$ achieved optimum tensile strength at $15 \mathrm{wt} \%$ banana fiber an increase of 65 and $68.9 \%$ over neat epoxy, for $10 \mathrm{~mm}$ and $20 \mathrm{~mm}$ length of the fiber respectively.

Meanwhile, kenaf fiber employed in present study had an optimum tensile at $20 \mathrm{wt} \%$, an enhancement of $72.9 \%$ over neat PP. It is noteworthy that $30 \mathrm{wt} \% \mathrm{KF}$ had a slight reduction of $3.2 \%$ in strength compared with value attained at $20 \mathrm{wt} \% \mathrm{KF}$. The reduction is fraternized by possible reduced stretching of fibers owing to 


\begin{tabular}{|l|l|r|r|r|l|}
\hline Source & DF & Adj SS & Adj MS & F-value & $P$ value \\
\hline $\mathrm{A}$ & 1 & 35.67 & 35.674 & 1.32 & 0.278 \\
\hline $\mathrm{B}$ & 1 & 238.52 & 238.523 & 8.81 & 0.014 \\
\hline $\mathrm{A}^{\star} \mathrm{A}$ & 2 & 237.57 & 118.787 & 4.39 & 0.043 \\
\hline $\mathrm{B}^{\star} \mathrm{B}$ & 1 & 4.84 & 4.844 & 0.18 & 0.681 \\
\hline $\mathrm{A}^{\star} \mathrm{B}$ & 1 & 158.59 & 158.593 & 5.86 & 0.036 \\
\hline Error & 1 & 871.28 & 871.283 & 32.19 & 0.000 \\
\hline Total & 10 & 270.70 & 27.070 & & \\
\hline
\end{tabular}

Table 4. ANOVA for impact strength.

\begin{tabular}{|l|l|r|r|c|l|}
\hline Source & DF & Adj SS & Adj MS & F-value & $P$ value \\
\hline $\mathrm{A}$ & 1 & 11.82 & 11.816 & 1.33 & 0.276 \\
\hline $\mathrm{B}$ & 1 & 133.44 & 133.444 & 14.99 & 0.003 \\
\hline $\mathrm{A}^{*} \mathrm{~A}$ & 1 & 0.06 & 0.063 & 0.01 & 0.935 \\
\hline $\mathrm{B}^{\star} \mathrm{B}$ & 1 & 91.65 & 91.648 & 10.30 & 0.009 \\
\hline $\mathrm{A}^{*} \mathrm{~B}$ & 1 & 158.72 & 158.724 & 17.83 & 0.002 \\
\hline Error & 10 & 89.02 & 8.902 & & \\
\hline Total & 15 & 1048.35 & & & \\
\hline
\end{tabular}

Table 5. ANOVA for compressive strength.

\begin{tabular}{|l|l|r|r|r|l|}
\hline Source & DF & \multicolumn{1}{|c|}{ Adj SS } & Adj MS & F-value & Pvalue \\
\hline A & 1 & 2.56 & 2.565 & 0.33 & 0.576 \\
\hline $\mathrm{B}$ & 1 & 155.18 & 155.182 & 20.24 & 0.001 \\
\hline $\mathrm{A}^{\star} \mathrm{A}$ & 1 & 14.52 & 14.516 & 1.89 & 0.199 \\
\hline $\mathrm{B}^{\star} \mathrm{B}$ & 1 & 12.23 & 12.230 & 1.60 & 0.235 \\
\hline $\mathrm{A}^{\star} \mathrm{B}$ & 1 & 394.72 & 394.723 & 51.48 & 0.000 \\
\hline Error & 10 & 76.67 & 7.667 & & \\
\hline Total & 15 & 1186.86 & & & \\
\hline
\end{tabular}

Table 6. ANOVA for flexural strength.

frictional interaction between the two input materials. 5, 10, 20, and $30 \mathrm{wt} \% \mathrm{KF}$ resulted in 11.0, 36.4, 72.9, and $62.3 \%$.

Evidently, in mix 4 composites (4 wt\% PSS), it is observed that KF loading demonstrated an uptrend in tensile strength from 5 to $20 \mathrm{wt} \%$. Further addition of $30 \mathrm{wt} \% \mathrm{KF}$ manifested slight depreciation in strength. By comparison, the tensile strength of mix 4 composites reinforced with 5 and $10 \mathrm{wt} \% \mathrm{KF}$ yielded 8.5 and $3.9 \%$ lesser than their counterpart in mix 2 depicting the fact that the coalesce of $2 \mathrm{wt} \%$ PSS and 5 and $10 \mathrm{wt} \% \mathrm{KF}$ amounts to strong cohesion and even stress distribution within the PP matrix as observed in Fig. 3a,b. Mixing of 4 wt\% PSS with 20 and $30 \mathrm{wt} \% \mathrm{KF}$ evoked 4.2 and $13.0 \%$ decrease in tensile strength as compared with their counterpart in mix 2. As highlighted in Fig. 6 concerning mix 10 composites (10 wt $\%$ PSS), the mix of 5 to $20 \mathrm{wt} \% \mathrm{KF}$ had a decrease in strength for 5 to $20 \mathrm{wt} \%$ based on a corollary of PSS coagulation and fiber entanglement as noted in Fig. 3i-l respectively. Evaluating performance of PSS on tensile strength; in general, PSS addition performed low on tensile strength in that its presence led to a decrease in strength (apart from when 4\% PSS was co-blended with 5 and $10 \mathrm{wt} \% \mathrm{KF}$ ). The poor performance of PSS on tensile strength is reported by Okafor et al. ${ }^{62}$ in which 5 , $10,15,20$, and $25 \mathrm{wt} \%$ led to the progressive decrease in strength associated with possible stress concentration at particulate/matrix boundary. By contrast, the $10 \mathrm{wt} \%$ chitosan microparticle from Daramola et al. ${ }^{48}$ yielded $\sim 30 \%$ improvement in tensile strength and compared with optimum enhancement of $72.9 \%$ in present study. The discrepancy may be on account of kenaf fiber distribution within matrix which aided stress distribution.

Statistical analysis. The representative results for the statistical data showing the ANOVA results for hardness, impact strength, compressive strength, flexural strength, and Tensile strength are as presented in Tables 3 , 4, 5, 6, and 7 respectively. Accordingly, the Pareto chart for hardness, impact strength, compressive strength, flexural strength, and Tensile strength are as displayed in Figs. 7, 8, 9, 10, and 11 respectively.

A represents kenaf fiber input (KF), B represents particulate snail shell input (PSS). 


\begin{tabular}{|l|l|r|r|l|l|}
\hline Source & DF & \multicolumn{1}{|c|}{ Adj SS } & Adj MS & F-value & P value \\
\hline $\mathrm{A}$ & 1 & 168.69 & 168.686 & 12.88 & 0.005 \\
\hline $\mathrm{B}$ & 1 & 391.11 & 391.109 & 29.86 & 0.000 \\
\hline $\mathrm{A}^{\star} \mathrm{A}$ & 1 & 26.17 & 26.172 & 2.00 & 0.188 \\
\hline $\mathrm{B}^{\star} \mathrm{B}$ & 1 & 63.90 & 63.903 & 4.88 & 0.052 \\
\hline $\mathrm{A}^{\star} \mathrm{B}$ & 1 & 306.22 & 306.219 & 23.38 & 0.001 \\
\hline Error & 10 & 130.98 & 13.098 & & \\
\hline Total & 15 & 2178.93 & & & \\
\hline
\end{tabular}

Table 7. ANOVA for tensile strength.

\section{Pareto Chart of the Standardized Effects} (response is Hardness, $\alpha=0.05$ )

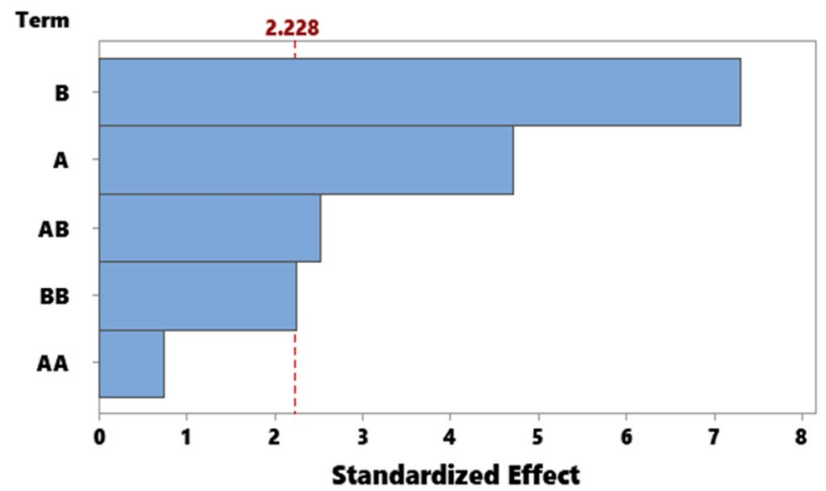

Figure 7. Pareto chart for hardness.

\section{Pareto Chart of the Standardized Effects (response is Izod impact strength, $\alpha=0.05$ )}

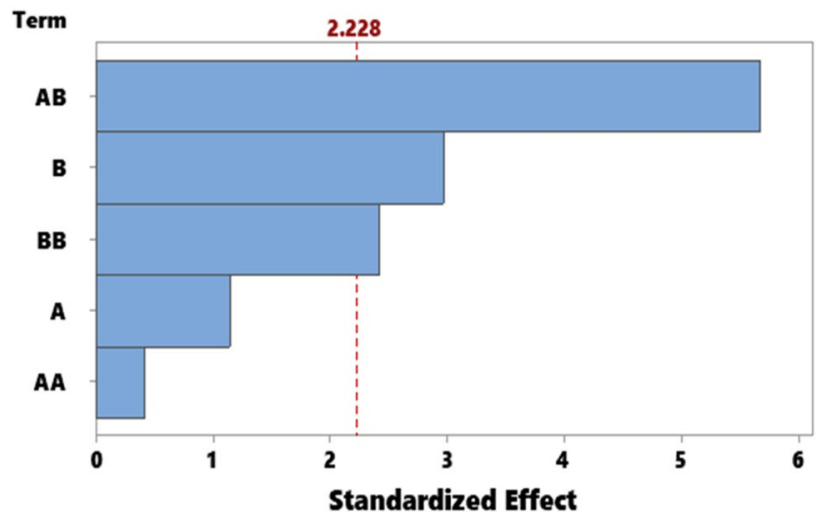

Figure 8. Pareto chart for impact strength.

From Table 3, the P-value of inputs A and B are $<0.05$ implying that at $95 \%$ confidence level, the contribution of KF and PSS on hardness was significant. Similarly, the interaction of $A^{\star} B$ is significant while interactions $A^{\star} A$ and $\mathrm{B}^{\star} \mathrm{B}$ are insignificant at $95 \%$ confidence level. The order in which the parameters identified $\left(\mathrm{A}, \mathrm{B}\right.$, and $\left.\mathrm{A}^{\star} \mathrm{B}\right)$ in the ANOVA table affect hardness is presented in the Pareto chart in (Fig. 7). The red line which points to 2.228 indicates the $95 \%$ confidence level, therefore, bars above line 2.228 depict parameters that play a significant role while the ones below, points to insignificant parameters. As observed in Fig. 7, parameter B is the most significant implication of which shows that particulate snail shells had a significant contribution to hardness. Next to PSS is Kenaf fiber followed by the interaction kenaf fiber * particulate snail shell.

Statistical analysis on impact strength is represented by ANOVA (Table 4) and Pareto chart (Fig. 8). From Table 4, parameters $B, A^{\star} A$, and $A^{\star} B$ significantly affect impact strength at the confidence level of 0.95 or $95 \%$ 
Pareto Chart of the Standardized Effects

(response is Compressive strength, $\alpha=\mathbf{0 . 0 5}$ )

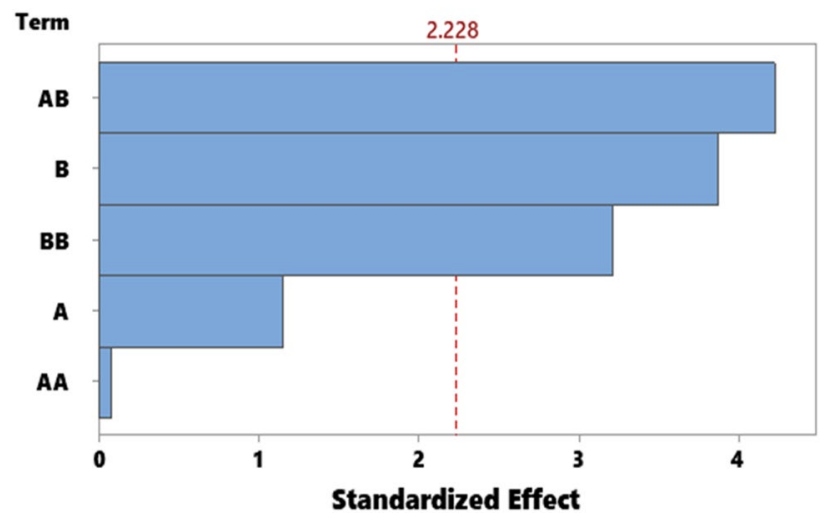

Figure 9. Pareto chart for compressive strength.

\section{Pareto Chart of the Standardized Effects}

(response is Flexural strength, $\alpha=\mathbf{0 . 0 5}$ )

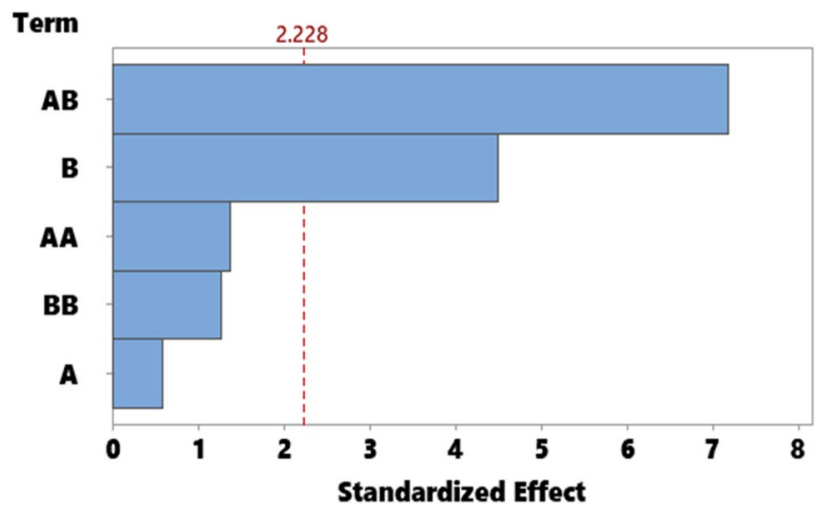

Figure 10. Pareto chart for flexural strength.

\section{Pareto Chart of the Standardized Effects \\ (response is Tensile strength, $\alpha=0.05$ )}

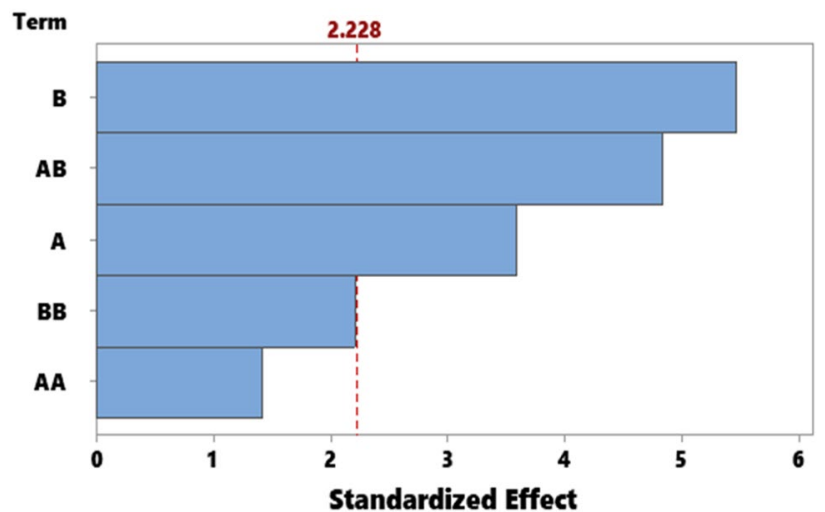

Figure 11. Pareto chart for tensile strength. 
while parameters $A$ and $\mathrm{B}^{\star} \mathrm{B}$ had an insignificant effect on the strength. Figure 8 which highlighted the order of magnitude of the parameters based on frequency reveals particulate snail shell is the most significant input. Kenaf fiber ${ }^{\star}$ particulate snail shell interaction is next followed by kenaf fiber. Parameters $B{ }^{\star} B$ and $A * A$ are insignificant.

As for compressive strength, contributions of particulate snail shell and interaction $B \star B, A^{\star} B$ had a significant effect on compressive strength (Table 5). Parameters $A$ and $A^{\star} A$ had no significant influence on the strength. The order of importance of the parameters according to (Fig. 9) are AB, B, and BB for significant parameters. Parameters A and AA are under the confidence level line 2.228, therefore had insignificant influence on strength value. Analysis of ANOVA for flexural strength (Table 6) showed that parameters B and AB significantly influence the value of flexural strength while the order of influence is $\mathrm{AB}$ and $\mathrm{A}$ according to the Pareto chart for compressive strength (Fig. 10).

Parameters A, B, and $\mathrm{A}^{\star} \mathrm{B}$ significantly influence tensile strength as depicted in (Table 6) while AA and BB displayed the insignificant influence of tensile strength. Meanwhile, the Pareto chart detected that $\mathrm{B}, \mathrm{AB}$, and $\mathrm{A}$ are in the order of the significant parameters (Fig. 11).

Taguchi analysis on each property. The various trend of the Taguchi analysis (main effect plot for $\mathrm{S} / \mathrm{N}$ ratios) on the experimental results is presented in Fig. 12a-f respectively.

Figure 12a reflects Taguchi's report on hardness from which the combination of $30 \mathrm{wt} \% \mathrm{KF}$ and $20 \mathrm{wt} \%$ PSS gave an optimal result for the property. As observed in Fig. 12b, the combination of $10 \% \mathrm{KF}$ and $10 \%$ PSS yielded optimum impact strength. Optimum for compressive, flexural, and tensile strengths are the combination of $10 \%$ KF and $4 \%$ PSS, $10 \% \mathrm{KF}$ and $2 \%$ PSS, and $20 \% \mathrm{KF}$ and $4 \%$ PSS.

Taguchi optimization was carried out simultaneously on hardness, impact strength, compressive, flexural, and tensile strengths using Minitab 19 application. It was applied to determine input parameters that will yield optimum performance for all properties. Figure $12 \mathrm{f}$ shows that kenaf fiber at $10 \mathrm{wt} \%$ and particulate snail shell at $4 \mathrm{wt} \%$ respectively shows optimum combined properties.

\section{Conclusions}

Kenaf fiber (KF) and particulate snail shell (PSS) were added to polypropylene (PP) matrix with the view of improving the mechanical properties for engineering application, the following conclusions were arrived at;

1. the blend of $2 \mathrm{wt} \%$ PSS and 5, 10, 20, and $30 \mathrm{wt} \% \mathrm{KF}$ ensued progressive enhancement of hardness, impact, compressive and flexural strength with $2 \mathrm{wt} \% \mathrm{PSS} / 30 \mathrm{wt} \%$ yielding 14.9, 46.4, 27.5, and 53.4\% for each property respectively. For flexural strength, optimum improvement was attained when $2 \mathrm{wt} \%$ PSS was combined with $30 \mathrm{wt} \%$ KF. Meanwhile, tensile strength achieved an optimum improvement of $72.9 \%$ when $2 \mathrm{wt} \%$ PSS was combined with $20 \mathrm{wt} \% \mathrm{KF}$.

2. presence of $4 \mathrm{wt} . \%$ PSS, $5,10,20$, and $30 \mathrm{wt} \% \mathrm{KF}$ engendered progressive enhancement of hardness, $4 \mathrm{wt} \% \mathrm{KF}$ yielded 29.5 optimum improvements for impact strength while the same dosage yielded optimum enhancement of $36.9 \%$ over neat PP for compressive strength. Flexural strength was enhanced by admix of 5 and $10 \mathrm{wt} \% \mathrm{KF}$ even as further addition of 20 and $30 \mathrm{wt} \% \mathrm{KF}$ led to a depreciation in strength. Tensile strength showed progressive enhancement up to $20 \mathrm{wt} \% \mathrm{KF}$ before a further decline.

3. the blend of $10 \mathrm{wt} \%$ PSS and 5, 10, 20 and $30 \mathrm{wt} \% \mathrm{KF}$ triggered enhancement of hardness, the same proportion spawned downward trend in impact, compressive, flexural, and tensile strength as proportion KF increased from 5 to $30 \%$. Hence, intermix of $10 \mathrm{wt} \%$ PSS and kenaf fiber from 5 to $30 \mathrm{wt} \%$ are detrimental to properties of PP matrix.

4. Taguchi optimization revealed an optimum mix proportion of $4 \mathrm{wt} \% \mathrm{PSS} / 10 \mathrm{wt} \% \mathrm{KF}$. Conclusively, particulate snail shell derived from African giant snail and kenaf bast fiber are good reinforcement in polypropylene in the development of a cost effective but stronger biocomposites which can find applications in automobile and aerospace application.

5. developed composite in this study showed better performance than their counterpart reinforced with hydroxylapatite and chitosan which are mostly used in reinforcement of biopolymers. 


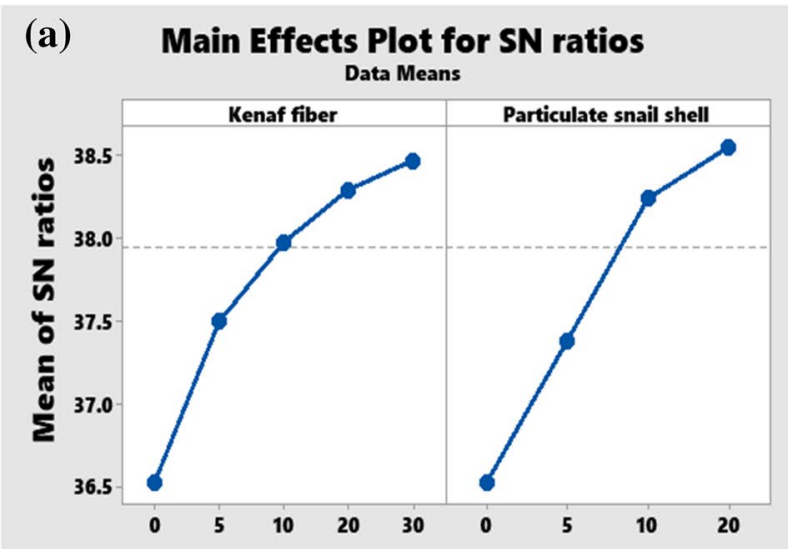

Signal-to-noise: Larger is better
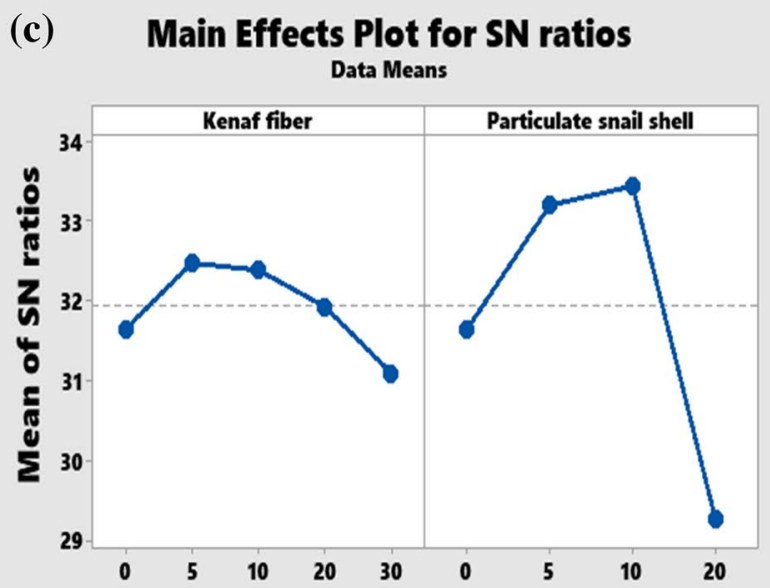

Signal-to-noise: Larger is better

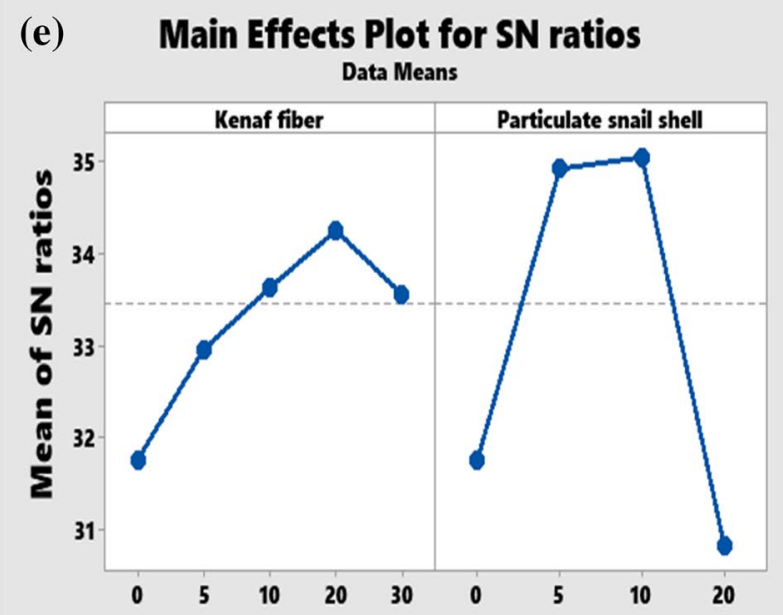

Signal-to-noise: Larger is better
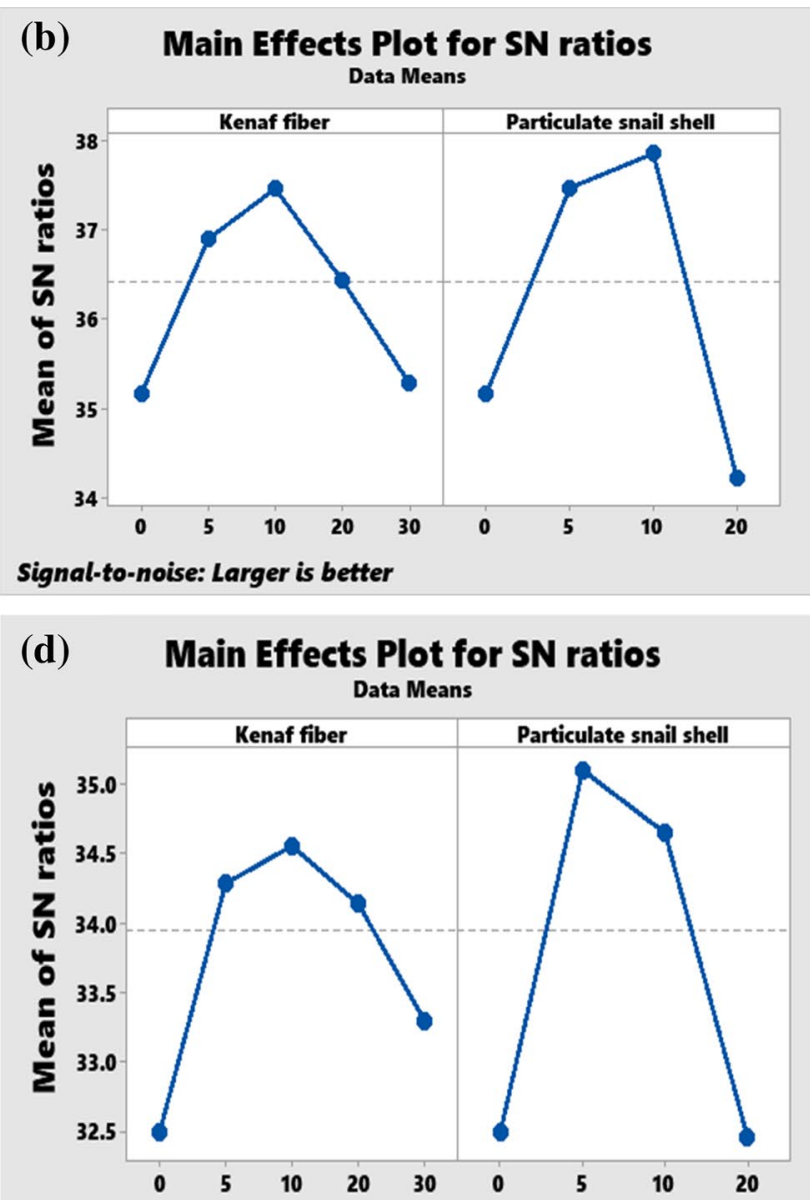

Signal-to-noise: Larger is better

(f) Experimental Main Effects Plot for SN ratios

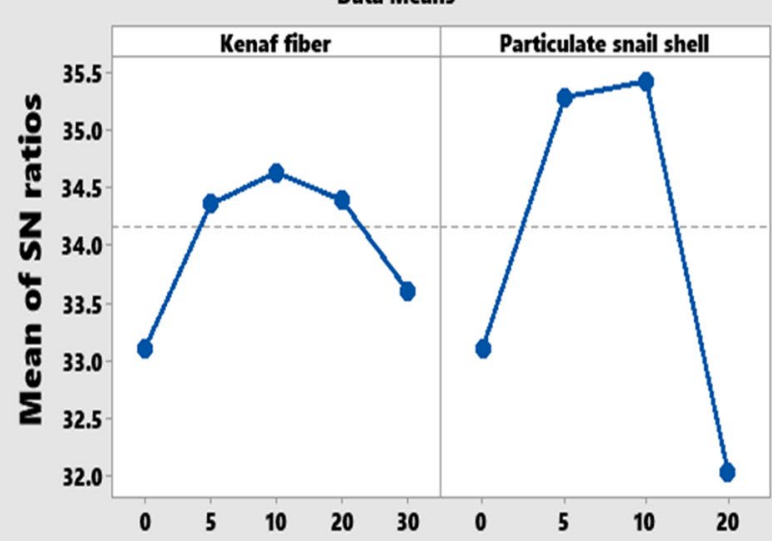

Signal-to-noise: Larger is better

Figure 12. Taguchi optimization.

Data availability

All data generated or analyzed during this study are included in this published article.

Code availability

No code was used for the computation of the data reported in this study. 
Received: 1 June 2021; Accepted: 19 January 2022

Published online: 15 February 2022

\section{References}

1. Dewidar, M. M., Yoon, H. C. \& Lim, J. K. Mechanical properties of metals for biomedical applications using powder metallurgy process: A review. Met. Mater. Int. 12(3), 193-206. https://doi.org/10.1007/BF030275 (2006).

2. Seuba, J., Deville, S., Guizard, C. \& Stevenson, A. J. Mechanical properties and failure behavior of unidirectional porous ceramics. Sci. Rep. 6(24326), 1-11. https://doi.org/10.1038/srep24326 (2015).

3. Plesa, I., Notingher, P. V., Schlogi, S., Sumereder, C. \& Muhr, M. Properties of polymer composites used in high-voltage applications. Polymers 8(173), 1-63. https://doi.org/10.3390/polym8050173 (2016).

4. Oladele, I. O., T. F. Omotosho, T. F. \& Adediran, A. A. Polymer-based composites: An indispensable material for present and future applications. Int. J. Polym. Sci. 2020(Article ID 8834518), 1-12. https://doi.org/10.1155/2020/8834518 (2020).

5. Gupta, G., Kumar, A., Tyagi, R. \& Kumar, S. Application and future of composite materials: A review. Int. J. Innov. Res. Sci. Eng. Technol. 5(5), 6907-6911 (2016).

6. Basheer, A. A. Advances in the smart materials applications in the aerospace industries. Aircr. Eng. Aerosp. Technol. 92(7), 10271035. https://doi.org/10.1108/AEAT-02-2020-0040 (2020).

7. Kalia, S., Averous, L., Njuguna, J. \& Nassiopoulos, E.. Cellulose-based bio-and nanocomposites. Int. J. Polym. Sci. Article ID837875, 1-35. https://doi.org/10.1155/2011/837875 (2011).

8. Luda, M. P., Brunella, V. \& Guaratto, D. Characterization of used PP-based car bumpers and their recycling properties. In International Scholarly Research Notices. 2013 Article ID 531093, 1-12. https://doi.org/10.1155/2013/531093 (2013).

9. Haque, M. M. U., Goda, K., Ogoe, S. \& Sunaga, Y. Fatigue analysis and failure reliability of polypropylene/wood flour composites. Adv. Ind. Eng. Polym. Res. 2, 136-142. https://doi.org/10.1016/j.aiepr.2019.07.001 (2019).

10. Maddah, H. A. Polypropylene as a promising plastic: A review. Am. J. Polym. Sci. 6(1), 1-11. https://doi.org/10.5923/j.ajps.20160 601.01 (2016).

11. Ayrilmis, N., Jarusombuti, S., Fueangvivat, V., Bauchongkol, P. \& White, R. H. Coir fiber reinforced polypropylene composite panel for automotive interior applications. Fibers Polym. 12(7), 919-926. https://doi.org/10.1007/s12221-011-0919-1 (2011).

12. Oladele, I. O. et al. Development of ecofriendly snail shell particulate-reinforced recycled waste plastic composites for automobile application. Sci. World J. 2020(7462758), 1-8. https://doi.org/10.1155/2020/7462758 (2020).

13. Shinde, N. G. \& Patel, D. M. A short review of automobile dashboard materials. IOP Conf. Ser. Mater. Sci. Eng. 810, 012033. https:// doi.org/10.1088/1757-899X/810/1/012033 (2020).

14. Luda, M. P., Brunella, V. \& Guaratto, D. Characterization of used PP-based car bumpers and their recycling properties. Int. Sch. Res. Not. 2013(531093), 1-12. https://doi.org/10.1155/2013/531093 (2013).

15. Shinde, N. G. \& Patel, D. M. A short review on automobile dashboard materials. IOP Conf. Seri. Mater. Sci. Eng. 810, 012033. https://doi.org/10.1088/1757-899X/810/1/012033 (2020).

16. Krzyzak, A., Mazur, M., Gajewski, M., Drozd, K., Komorek, A. \& Przbylek, P. Sandwich structured composites for aeronautics: Methods of manufacturing affecting some mechanical properties. Int. J. Aerosp. Eng. 2016 Article ID 7816912, 1-10. https://doi. org $/ 10.1155 / 2016 / 7816912(2016)$.

17. Vu, H. H., Do, T. G. \& Nguyen, T. T. The application of polypropylene fiber for reinforced concrete beams and slabs. IOP Conf. Ser. Mater. Scie. Eng. 869, 072042. https://doi.org/10.1088/1757-899X/869/7/072042 (2020).

18. Onuegbu, G. C. \& Igwe, I. O. The effects of filler contents and particle sizes on the mechanical and end-use properties of snail shell powder filled polypropylene. Mater. Sci. Appl. 2, 811-817. https://doi.org/10.4236/msa.2011.27110 (2011).

19. Onuegbu, G. C. \& Nwanonenyi, J. C. The effect of pulverized groundnut husk on some mechanical properties of polypropylene composites. Int. J. Engr. Sci. Invention. 2(6), 79-83 (2013).

20. Mark, V. C., Madufor, I. C., Obasi, H. C. \& Mark, U. Influence of filler loading on the mechanical and morphological properties of carbonized coconut shell particles reinforced polypropylene composites. J. Comp. Mater. 54(3), 397-407. https://doi.org/10.1177/ $0021998319856070(2020)$

21. Udhayasankar, R., Karthikeyan, B. \& Balaji, A. Comparative mechanical, thermal properties and morphological study on untreated and $\mathrm{NaOH}$-treated coconut shell-reinforced cardanol environmental-friendly green composites. J. Adhesi. Sci. Technol. https:// doi.org/10.1080/01694243.2020.1727643 (2020).

22. Hassan, S. B., Aigbodion, V. S. \& Patrick, S. N. Development of polyester/eggshell particulate composites. Tribol. Ind. 34(4), 217-225 (2012).

23. Balaji, A. et al. Study on mechanical and morphological properties of sisal/banana/coir fiber-reinforced hybrid polymer composites. J. Braz. Soc. Mech. Sci. Eng. 41(386), 1-10. https://doi.org/10.1007/s40430-019-1881-x (2019).

24. Balaji, A., Karthikeyan, B., Swaminathan, J. \& Sundar Raj, C. Thermal behavior of cardanol resin reinforced $20 \mathrm{~mm}$ long untreated bagasse fiber composites. Int. J. Polym. Anal. Charact. 23(1), 70-77. https://doi.org/10.1080/1023666X.2017.1387448 (2017).

25. Akinwande, A. A., Adeiza, A. A., Balogun, O. A., Daniel, P. T. \& Shittu, S. A. Property enhancement and optimization of polypropylene matrix for automobile application: Influence of coir fiber proportion and length. Int. J. Res. Acad. (Sci. Technol. Eng.) 6(10), $1-23(2020)$.

26. Lee, C. H., Sapuan, S. M. \& Hassan, M. R. Mechanical and thermal properties of kenaf reinforced polypropylene/magnesium hydroxide composites. J. Eng. Fibers Fabr. 12(2), 50-58 (2017).

27. Ramli, R., Yunus, R. M., Beg, M. D. H. \& Prasad, D. M. R. Oil palm fiber reinforced polypropylene composites: Effects of fiber loading and coupling agents on mechanical, thermal and interfacial properties. J. Comp. Mater. 46(11), 1275-1284. https://doi. org $/ 10.1177 / 0021998311417647$ (2011).

28. Kabir, M. A., Huque, M. N., Islam, M. R. \& Bledzki, A. K. Mechanical properties of jute fiber reinforced polypropylene composites. Effect of chemical treatment by benzenedia zonium salt in alkaline medium. Bioresources 5(3), 1618-1625 (2010).

29. Balaji, A., Purushothaman, R., Udhayasankar, R., Vijayaraj, S. \& Karthikeyan, B. Study on mechanical, thermal, and morphological properties of banana-fiber-reinforced epoxy composites. J.Bio Tribo Corros. 6(60), 1-10. https://doi.org/10.1007/s40735-02000357-8 (2020).

30. Adediran, A. A., Akinwande, A. A., Balogun, O. A., Olasoju, O. S. \& Adesina, O. S. Experimental evaluation of bamboo fiber/ particulate coconut shell hybrid PVC composite. Sci. Rep. 11(5465), 1-15. https://doi.org/10.1038/s41598-021-85038-3 (2021).

31. Adeosun, S. O., Akpan, E. I. \& Akanegbu, H. A. Thermo-mechanical properties of unsaturated polyester reinforced with coconut and snail shells. Int. J. Comp. Mater. 5(3), 52-64. https://doi.org/10.5923/j.cmaterials.20150503.02 (2015).

32. Salman, S. D., Leman, Z., Sultan, M. T. H., Ishak, M. R. \& Cardona, F. Influence of fiber content on mechanical and morphological properties of woven kenaf reinforced PVB film produced using a hot press technique. Int. J. Polym. Sci. 2016(7828451), 1-11. https://doi.org/10.1155/2016/7828451 (2016).

33. Chris-Okafor, P. U., Nwokoye, J. N., Oyom, P. O. \& Ilodigwe, C. B. Effects of snail shell powder on the mechanical properties of low-density polyethylene (LDPE). Lond. J. Res. Sci. Nat. Formal. 18(4), 7-12 (2018).

34. Adediran, A. A. et al. Effect of surface modification on the properties of polypropylene matrix reinforced with coir fiber and yam peel particulate. Sci. World J. 8891563, 1-12. https://doi.org/10.1155/2021/8891563 (2021). 
35. ASTM D 256-10. Standard Test METHOD for Determining the Izod Pendulum Impact Resistance of Plastics (ASTM International, West Conshohocken, PA, 2017). https://doi.org/10.1520/D0256-10.

36. ASTM D3039/D3039M-17. Standard Test Method for Tensile Properties of Polymer Matrix Composite Materials (ASTM International, West Conshohocken, PA, 2017). https://doi.org/10.1520/D3039_D3039M-17.

37. ASTM D790-17. Standard Test Methods for Flexural Properties of Unreinforced and Reinforced Plastics and Electrical Insulating Materials (ASTM International, West Conshohocken, PA, 2017). https://doi.org/10.1520/D0790-17.

38. ASTM D 2240-15e1. Standard Test Method Rubber Property-Durometer Hardness (ASTM International, West Conshohocken, PA, 2015). https://doi.org/10.1520/D2240-15E01.

39. ASTM D 695-15. Standard Test Method Compressive Properties of Rigid Plastics (ASTM International, West Conshohocken, PA, 2015). https://doi.org/10.1520/D0695-15.

40. S. Siddika, F. Mansura, M. Hasan and A. Hassan. Effect of reinforcement and chemical treatment of fiber on the properties of jutecoir fiber reinforced hybrid polypropylene composites. Fibers and Polymers. 15(5), (2014).1023-1028. https://doi.org/10.1007/ s12221-014-1023-0.

41. Mir, S. S., Hasan, M., Hasan, S. M. N., Hossain, Md. J. \& Nafsin, N. Effect of chemical treatment on the properties of coir fiber reinforced polypropylene and polyethylene composites. Polym. Compos. https://doi.org/10.1002/pc.23690 (2015).

42. Durowaye, S. I., Lawal, G. I., Lawal, M. A. \& Durowaye, V. O. Mechanical properties of particulate coconut shell and palm fruit polyester composites. Int. J. Mater. Eng. 4(4), 141-147. https://doi.org/10.5923/j.ijme.20140404.04 (2014).

43. Swain, P. T. R. \& Biswas, S. Abrasive wear behaviour of surface modified jute fiber reinforced epoxy composites. Mater. Res. 20(3), 661-674. https://doi.org/10.1590/1980-5373-MR-2016-0541 (2017).

44. Chelliah, A. Mechanical properties and abrasive wear of different weight percentages of TiC filled basalt fabric reinforced epoxy composites. Mater. Res. 22(2), e20180431, 1-8. https://doi.org/10.1590/1980-5373-MR-2018-0431 (2019).

45. Nwanonenyi, S. C., Obidiegwu, M. U. \& Onegbu, G. C. Effects of particle sizes, filler contents, and compatibilization on the properties of linear low-density polyethylene filled periwinkle shell powder. Int. J. Eng. Sci. 2(2), 1-8 (2013).

46. Anuar, H., Hassan, N. A. \& Fauzey, F. M. Compatibilized PP/EPDM-kenaf fiber composite using melt blending method. Adv. Mater. Res. 264-265, 743-747. https://doi.org/10.4028/www.scientific.net/AMR.264-265.743 (2011).

47. Kim, J. \& Cho, D. Effects of waste expanded polypropylene as a recycled matrix on the flexural, impact, and heat deflection temperature properties of kenaf fiber/polypropylene composites. Polymers 12(2578), 1-11. https://doi.org/10.3390/polym12112578 (2020).

48. Daramola, O. O. et al. Mechanical and wear behavior of polylactic acid matrix composites reinforced with crab-shell synthesized chitosan microparticles. Mater. Today Proc. 38(2021), 999-1005. https://doi.org/10.1016/j.matpr.2020.05.599 (2021).

49. Husseinsyah, S., Amri, F., Husin, K. \& Ismail, H. Mechanical and thermal performance of chitosan-filled polypropylene composite: The effect of acrylic acid. J. Vinyl Add. Tech. https://doi.org/10.1002/vnl20268 (2011).

50. Amri, F., Husseinsyah, S. \& Hussin, K. Mechanical, morphological and thermal properties of chitosan filled polypropylene composites: The effect of binary modifying agents. Comp. Part A 46, 89-95. https://doi.org/10.1016/j.compositesa.2012.10.014 (2013).

51. Dash, M. A study on thermal characteristics of epoxy composites filled with natural fiber and particulate. M. Tech. A thesis submitted in Department of Mechanical Engineering, National Institute of Technology, Rourkela, India (2016).

52. Li, X., Tabil, L. G. \& Panigrahi, S. Treatment of natural fiber for use in natural fiber-reinforced composites: A review. J. Polym. Environ. 15, 25-33. https://doi.org/10.1007/s10924-006-0042-3 (2007).

53. Eng, C. C., Ibrahim, N. A., Zainuddin, N., Ariffin, H. \& Yunus, W. M. Z. W. Impact strength and flexural properties enhancement of methacrylate silane treated oil palm mesocarp fiber reinforced biodegradable hybrid composites. Sci. World J. 2014(213180), 1-8. https://doi.org/10.1155/2014/213180 (2014).

54. Mohammed, L., Ansari, M. N. M., Pua, G., Jawaid, M. \& Islam, M. S. A review on natural fiber reinforced polymer composite and its applications. Int. J. Polym. Sci. 2015(243947), 1-15. https://doi.org/10.1155/2015/243947 (2015).

55. Sushanta, K. S., Mohanty, S. \& Nayak, S. K. Banana/glass fiber reinforced polypropylene hybrid composites: Fabrication and performance evaluation. Polym. Plast. Technol. Eng. 48, 397-414 (2009).

56. Obasi, H. C. Peanut husk filled polyethylene composites: Effects of filler content and compatibilizer on properties. J. Polym. 2015(189289), 1-9. https://doi.org/10.1155/2015/189289 (2005).

57. Asuke, F. et al. Effects of a bone particle on the properties and microstructure of polypropylene/bone ash particulate composite. Res. Phys. 2, 135-141 (2012).

58. Shyang, C. W., Khim, L. Y., Ariffin, A., Arifin, Z. \& Ishak, M. Flexural properties of hydroxyapatite reinforced poly (methyl methacrylate) composites. J. Reinf. Plast. Compos. 27(945), 945-952. https://doi.org/10.1177/0731684407086506 (2008).

59. Haque, M. M., Hasan, M., Islam, M. S. \& Ali, M. E. Physicomechanical properties of chemically treated palm and coir fiber reinforced polypropylene composites. Biores. Technol. 100, 4903-4906. https://doi.org/10.1016/j.biortech.2009.04.072 (2009).

60. Haque, M. et al. Coir fiber reinforced polypropylene composites: Physical and mechanical properties. Adv. Compos. Mater 19(2010), 91-106. https://doi.org/10.1163/092430409X12530067339325 (2010).

61. Haque, M. M. \& Islam, M. N. A study on the mechanical properties of urea treated coir reinforced polypropylene composites. J. Thermoplast. Compos. Mater. 26(2), 139-155. https://doi.org/10.1177/0892705711419698 (2011).

62. Okafor, P. U. C., Okonkwo, C. C. \& Ohaeke, M. S. Reinforcement of high-density polyethylene with snail shell powder. Am. J. Polym. Sci. 8(1), 17-21. https://doi.org/10.5923/j.ajps.20180801.03 (2018).

\section{Acknowledgements}

Authors appreciate the Department of Metallurgical and Materials Engineering, Federal University of Technology, Akure, Ondo State, Nigeria, and Landmark University SDGs- 17 Research Group (Partnership for the Goals) for their support.

\section{Author contributions}

A. A. A., A. A. A, and O. A. B wrote the main manuscript text O. S. B, M. K. A., O. S. A., and A. A. O prepared figures. All authors reviewed the manuscript.

\section{Funding}

Authors receive no direct funding for the current study.

\section{Competing interests}

The authors declare no competing interests.

\section{Additional information}

Correspondence and requests for materials should be addressed to A.A.A. or A.A.A. 
Reprints and permissions information is available at www.nature.com/reprints.

Publisher's note Springer Nature remains neutral with regard to jurisdictional claims in published maps and institutional affiliations.

(c) (i) Open Access This article is licensed under a Creative Commons Attribution 4.0 International License, which permits use, sharing, adaptation, distribution and reproduction in any medium or format, as long as you give appropriate credit to the original author(s) and the source, provide a link to the Creative Commons licence, and indicate if changes were made. The images or other third party material in this article are included in the article's Creative Commons licence, unless indicated otherwise in a credit line to the material. If material is not included in the article's Creative Commons licence and your intended use is not permitted by statutory regulation or exceeds the permitted use, you will need to obtain permission directly from the copyright holder. To view a copy of this licence, visit http://creativecommons.org/licenses/by/4.0/.

(c) The Author(s) 2022 